\title{
Expression of pS2 in prostate cancer correlates with grade and Chromogranin A expression but not with stage
}

\author{
M Hammad Ather*1, Farhat Abbas ${ }^{1}$, Nuzhat Faruqui ${ }^{1}$, M Israr $^{2}$ and \\ Shahid Pervez ${ }^{2}$
}

Address: ${ }^{1}$ Dept. of Surgery, Aga Khan University, Karachi, Pakistan and 2Dept. of Pathology, Aga Khan University, Karachi, Pakistan

Email: M Hammad Ather* - hammad.ather@aku.edu; Farhat Abbas - farhat.abbas@aku.edu; Nuzhat Faruqui - nuzhat.faruqui@aku.edu; M Israr - mohammad.israr@aku.edu; Shahid Pervez - shahid.pervez@aku.edu

* Corresponding author

Published: 10 December 2004

BMC Urology 2004, 4:14 doi:10.1 186/147/-2490-4-14
Received: 22 September 2003

Accepted: 10 December 2004

This article is available from: http://www.biomedcentral.com/I47/-2490/4/14

(c) 2004 Ather et al; licensee BioMed Central Ltd.

This is an Open Access article distributed under the terms of the Creative Commons Attribution License (http://creativecommons.org/licenses/by/2.0), which permits unrestricted use, distribution, and reproduction in any medium, provided the original work is properly cited.

\begin{abstract}
Background: The biological potential of prostate cancer is extremely variable. Particular interest is focused on markers not expressed in normal prostatic tissues. pS2 protein expression has been demonstrated in a range of malignant tissues in an oestrogen-independent pathway. Recently, it has been demonstrated that $\mathrm{PS} 2$, in prostate cancer, is closely associated with neuro-endocrine differentiation. In the present study, we have analyzed, the potential of Neuro-endocrine and pS2 (TFFI) expression in human prostate cancer determined by immunohistochemistry, in primary adenocarcinoma of the prostate and attempted to correlate this with the clinico-pathologic features of the patient and neuroendocrine expression.
\end{abstract}

Methods: Ninety-five malignant prostatic specimens from primary adenocarcinoma, obtained from either transurethral resection of prostate or radical retropubic prostatectomy, from 84 patients between January $199 \mathrm{I}$ and December 1998 were evaluated by immuno-histochemical staining using selected neuroendocrine tumor markers i.e. chromogranin $\mathrm{A}(\mathrm{CgA})$ and estrogen inducible pS2 protein. The relationship between the expressions of pS2 was studied with CgA expression, clinical stage (TNM) and tumour grade (Gleason system). Fischer exact test was used for statistical analysis.

Results: The mean age of the patients was $70+/-9.2$ years. The pS2 expression was seen in $10 \%$ of primary prostate cancers. Worsening histological grade was associated with greater expression of $\mathrm{pS} 2(\mathrm{p}<0.001)$. The expression of $\mathrm{CgA}$ was noted in $31 \%$ of malignant prostatic tissue. In $\mathrm{PS} 2$, positive cases $2 / 3 r d$ of patients were also $\mathrm{CgA}+v e$. However, there was no significant correlation between PS2 expression and the stage of disease.

Conclusion: pS2 expression in prostate cancer significantly correlates with histological grade and the neuroendocrine differentiation, as demonstrated by Chromogranin A expression but not with the clinical stage of the disease. However, the overall expression was low consequently; no definitive conclusions can be drawn. We feel further work is required in a larger series, both in primary and metastatic cancer. 


\section{Background}

The biological potential of prostate cancer is extremely variable [1]. It is perhaps the only cancer, which could be managed by, deferred treatment in its early course for selected cancers [2]. To define the biological potential of prostate cancer, prognostic markers are employed. There are numerous markers for assessing the biological aggressiveness of the prostate cancer [3]. However, large studies have shown that they lack sensitivity and specificity due primarily to their expression in normal prostatic epithelium as well. This justifies a recent surge in interest in markers specific to malignant prostatic tissue [4]. Recent studies have shown the potential of neuro-endocrine differentiation in adenocarcinoma of the prostate and its role in ascertaining the biological aggressiveness of the tumor [3]. Wang et al [5] has recently noted that the expression of the pS2 protein is implicated in the pathogenesis and progression of some neuro-endocrine tumors.

Maisakowski et al. first described the pS2 gene in the MCF-7 human breast cancer cell line [6]. The pS2 is a cysteine rich secretory protein, containing 84 amino acids and a molecular weight of $6.45 \mathrm{k}$-Da. The pS2 gene is highly expressed in estrogen-receptor positive breast cancer, and high levels of pS2 protein correlate with responsiveness to primary endocrine therapy and better patient survival in breast cancer. However, in prostate cancer it is linked with NE differentiation and poorer outcome [7].

In the present study, we have investigated the expression of pS2 in malignant primary prostatic tissue in specimens obtained from transurethral, open prostatectomy, and correlated this with neuro-endocrine differentiation and clinical stage and grade. This is a preliminary report on pS2 expression in prostate cancer, a larger study will better define the correlation between stage, grade of cancer with pS2 and CgA expression.

\section{Methods}

\section{Demographic profile}

Ninety-five malignant consecutive primary prostatic specimens were obtained from 84 patients by either trans-urethral resection of prostate ( $\mathrm{n}=69$ patients) for urinary obstruction or from radical retro-pubic prostatectomy ( $\mathrm{n}$ = 15 patients) between January 1991 and December 1998 . These tissue specimens were taken from the archived records of the department of pathology. The age ranged from $52-93$ years (mean $70+9.2$ years).

Immuno-histochemical staining for pS2 and Chromogranin A Sections were stained for $\mathrm{H} \& \mathrm{E}$ as well as for pS2 (Novocastra, UK Cat. \# NCL-pS2) and Chromogranin A (DAKO, Glostrup, Denmark Cat \# A0430) by immunohistochemistry using indirect immunoperoxidase technique.
Briefly, $3 \mu \mathrm{m}$ thick tissue sections were cut and mounted on poly-L-lysine (sigma) coated slides. Sections were deparaffinized in xylene and re-hydrated through graded alcohol series followed by water. Antigen retrieval was done in case of pS2 with $10 \mathrm{mM}$ citrate buffer, 6.0 in a microwave oven $3 \times 5$ seconds at $450 \mathrm{~W}$, then gradually cooled down to room temperature.

Sections were washed with water followed by Phosphate buffer saline (PBS) rinse.

Endogenous peroxidase in the sections was blocked for 30 minutes with $0.3 \% \mathrm{H} 202$ in methanol. Sections were washed with PBS. All sections were treated with Normal Swine serum (NSS) prediluted 1:10 in PBS for 5 minutes. The sections were then incubated with the primary antibody to pS2 diluted with NSS (1:100) and Chromogranin A (1:20) for 90 minutes at room temperature. Slides were washed with PBS and incubated with peroxidase-conjugated swine anti rabbit secondary antibody (DAKO) at a dilution of 1:150 for 45 minutes at room temperature. 3, 3'-diaminobenzidine (DAB) was used as a final Chromogen. Harris Haemtoxylin was used as a counter nuclear stain. Positive and negative controls were used with all batches of IHC staining. A prostatic adenocarcinoma specimen section expressing pS2 was used as a positive control. Same case exhibiting the primary antibody was used a negative control with each staining procedure. The extent of pS2 reactivity was semi quantitatively assessed by estimating the percentage of positive acini present in the whole mounted sessions. Expression was graded ++ if more than $50 \%$ of the tissue showed expression, + if between 5 and $49 \%$ showed expression and focal if $<5 \%$ showed expression.

Histological grading The Gleason system was used for grading of the cancer specimens; a senior histopathologist (SP) blinded of previous Gleason grading and clinical course did this. Based upon the Gleason score patients were divided into three groups i.e. well differentiated (Gleason sum 2-4), moderately differentiated (Gleason sum 5-7) and poorly differentiated (Gleason sum 8-10).

To study correlation and determine the p value Student $\mathrm{t}$ test was applied.

\section{Results}

The cancerous lesion composed of 35\% ( $n=29)$ stage T1, $32 \%(\mathrm{n}=27)$ stage $\mathrm{T} 2,25 \%(\mathrm{n}=21)$ stage $\mathrm{T} 3$ and $6 \%(\mathrm{n}$ $=5$ ) stage T4 disease according to the TNM classification. Based upon the stage of the disease patients were divided into three groups i.e. organ confined (T1-2), locally invasive (T3-4 and N1) and metastatic (M1) cancer. 


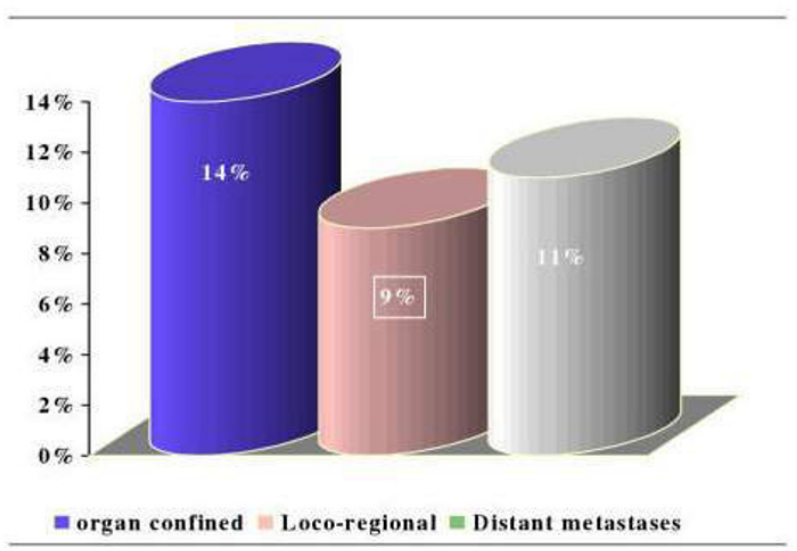

\section{Figure I}

Expression of pS2 \% in organ confined, locally advanced (locoregional) and metastatic adenocarcinoma of the prostate.

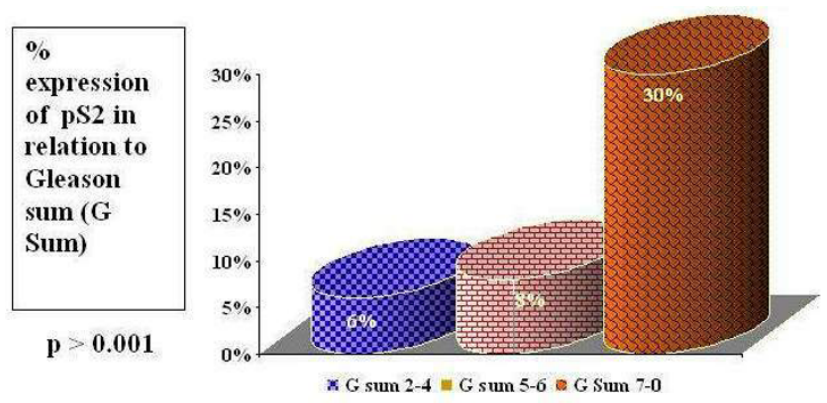

Figure 2

Correlation of Gleason sum and pS2 expression.

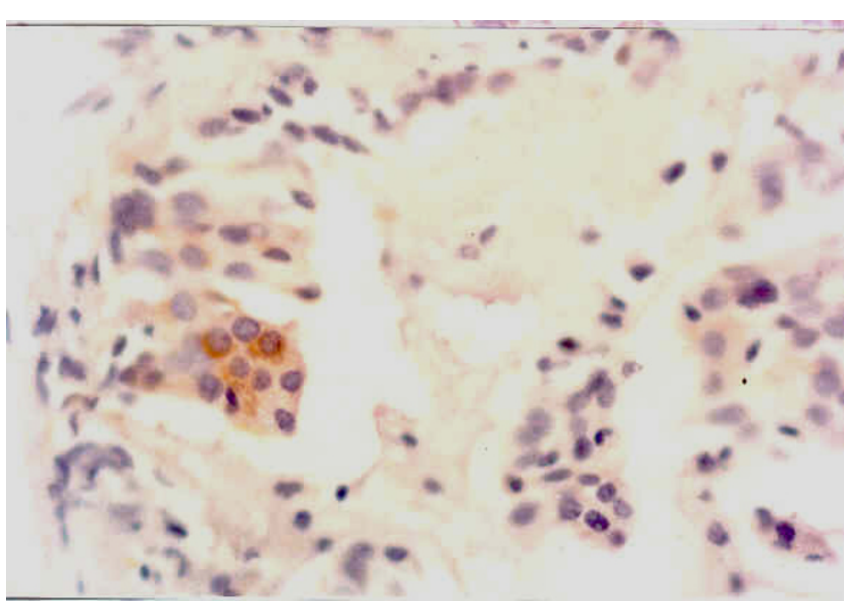

Figure 4

Photomicrograph of prostatic adenocarcinoma stailed with a polyclonal against pS2. Note prominent perinuclear brown staining in tumour cells. Magnification: 40x

Table I: Correlation of $\mathrm{pS} 2$ expression with CgA expression and Gleason sum (GS)

\begin{tabular}{lcccc}
\hline & n (\%) & CgA +ve & CgA -ve & Mean GS \\
\hline PS2 +ve. & $9(10)$ & $67 \%$ & $33 \%$ & 7.5 \\
PS2 -ve. & $86(90)$ & $28 \%$ & $72 \%$ & 6.2 \\
\hline
\end{tabular}

+ve. Expression positive -ve. Expression negative CgA Chromogranin A GS Gleeson sum

Worsening histological grade was associated with greater expression of pS2. In Gleason sum groups 2-4 and 5-6, expression of pS2 was noted in 6 and $8 \%$ respectively whereas in Gleason sum group 8-10 the expression was observed in $30 \%(\mathrm{p}<0.001)$. The expression of pS2 [figure 4(a) and 4(b)] in various prognostically and therapeutically distinct groups based upon the grade of cancer is described in figure 2.

\section{Discussion}

In the present study, we investigated the expression of pS2 protein in the adenocarcinoma of prostate and in the surrounding normal prostate tissue. We used a standard immunohistochemical method to assess pS2 expression in tissue sections of adenocarcinoma prostate instead of instead of biochemical or immuno-radiometric assay. The immuno-histochemical method for detection of pS2 expression has drawbacks in comparison to biochemical and immunoradiometric assay on tissue extracts. Both of 
the later methods allow precise quantification of levels of expression for a better correlation with other parameters studied.

However, as we are interested in the clinical utility of pS2 expression in our prostate cancer population, we used immunohistochemistry, which allows appreciation of intra-tumoral heterogeneity of expression and of both cancerous and non-cancerous cells. pS2 protein expression has been demonstrated in a range of malignant and benign pathologies. It is highly expressed in receptor positive human breast cancer [5] but expression in other cancers like ovarian [7], cervical [8], gastrointestinal [9], thyroid [10] and bladder [11] is variable.

A significant implication of pS2 in prostate cancer is the close association of this marker with Neuroendocrine (NE) differentiation. There is increasing evidence that focal NE differentiation frequently occurs in prostatic adenocarcinoma and it may have significant prognostic implications [12-14]. NE differentiation is also described in hormone refractory prostate cancer; Krijnen et al [14] noted that androgen receptors are not present in prostatic adenocarcinoma staining positive for $\mathrm{CgA}$. While Higashiyama noted $17 \%$ expression of pS2 in all pulmonary cancers, Wang et al [5] noted $45 \%$ expression in small cell cancers of the lung (a neuroendocrine carcinoma). Recent evidence has suggested that expression of pS2 is closely associated with neuroendocrine differentiation in prostate cancer [15]. Colombel et al from in an RT-PCR study found a high expression of pS2 in prostate cancer; however, they found no correlation between with tumour stage or Gleason grade. Our present work [15] indicates that NE differentiation not only correlates with other prognostic markers like grade of the cancer but also has independent prognostic value. Bonkhoff et al [15] noted that pS2 expression was consistently confined to NE differentiation in untreated tumors and in carcinomas that relapsed after hormonal therapy. Our results have similarly shown that 6 out of 9 cancers that have expressed pS2 were also positive for $\mathrm{CgA}$.

\section{Conclusions}

Our results demonstrate that although the expression of pS2 protein was noted in only $1 / 10$ th of prostate cancers, it significantly correlates with the histological grade and NE differentiation; both have independent and interdependent prognostic value. There is dearth of data exploring the correlation of pS2 expression and aggressiveness of prostate cancer cell behavior. Limited literature available at present show significant association of $\mathrm{pS} 2$ expression with prognosis in prostate cancer, however more work is required to explore the utility of this marker in defining the biological potential of prostate cancer.

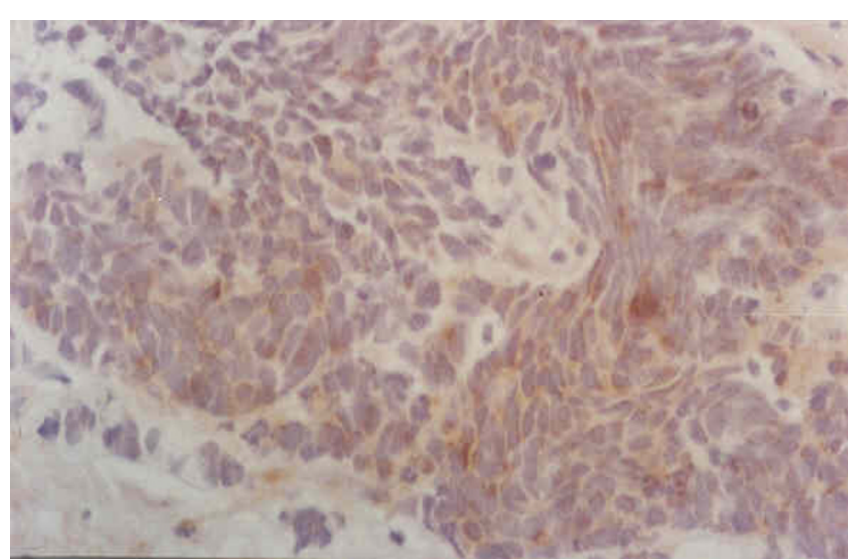

\section{Figure 3}

Photomicrograph of prostatic adenocarcinoma stained with polyclonal antibody against $\mathrm{CgA}$. Note prominent cytoplasmic staining within tumour cells. Magnification: $4 \times$

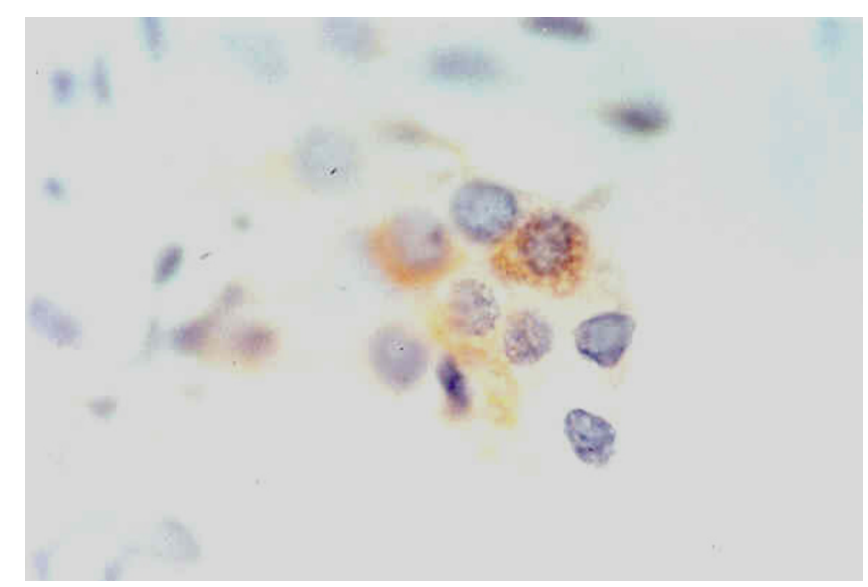

Figure 5

Photomicrograph of prostatic adenocarcinoma stailed with a polyclonal against pS2. Note prominent perinuclear brown staining in tumour cells. Higher magnification (100x).

\section{Competing interest}

The author(s) declare that they have no competing interests.

\section{Authors' contributions}

MHA, conceived of the idea, wrote the manuscript and conducted clinical part of the study. FA, helped in designing the study and reviewed the draft of the manuscript

$\mathrm{NF}$, helped in conducting study, helped in data collection and analysis. MI, conducted the pathological part of the 
study. SP, conducted and supervised the pathological aspects of the study and reviewed the manuscript and wrote methods and results related to the pathology. All authors' have read and approve of the final manuscript.

\section{References}

I. Harding MA, Theodorescu D: Prognostic markers in localized prostate cancer: from microscope to molecules. Cancer-Metastases-Rev 1999, 17(4):429-37.

2. Ather MH, Abbas F: Prognostic significance of neuroendocrine differentiation in prostate cancer. Eur Urol 2000, 38:535-42.

3. Brasso K, Frijis S, Juel K, Jorgensen T, Iversen P: Morbidity in patients with clinically localized prostate cancer managed with non-curative intent. A population based case control study. Prostate Cancer Prostatic Dis 1999, 2:253-256.

4. Erbersdobler A, Fritz H, Schnoger S, Graefen M, Hammereer P, Huland H, Henke RP: Tumor grade, proliferatio, apoptosis,microvessel density, $\mathrm{p} 53$, and bcl 2 in prostate cancers: differences between tumours located in the transition zone and in the peripheral zone. Eur Urol 2002, 41:40-6.

5. Yang Y, Chisholm GD, Habib FK: The distribution PSA, Cathep$\sin \mathrm{D}$ and $\mathrm{pS2}$ in BPH and cancer of the prostate. The Prostate 1992, 21:201-08.

6. Wang DG, Johnston CF, Liu WH, Sloan JM, Buchanan KD: Expression of abreast-cancer-associated protein (pS2) in human neuro-endocrine tumors. Int / Cancer 74(3):270-4. 1997 Jun 20

7. Masiakowski P, Breathnach R, Bloch J, Gannon F, Krust A, Chambon $P$ : Cloning of cDNA sequences of hormone-regulated genes from the MCF-7 human breast cancer cell line. Nucleic Acids Res I0(24):7895-903. 1982 Dec 20

8. Luqmani YA, Ryall G, Shousha S, Coombes RC: An immuno-histochemical survey of pS2 expression in human epithelial cancers. Int J Cancer 50(2):302-4. 1992 Jan 21

9. Looi LM, Azura WW, Cheah PL, Ng MH: pS2 expression in infiltrating ductal carcinoma of the breast correlates with oestrogen receptor positivity but not with histological grade and lymph node status. Pathology 200I, 33(3):283-6.

10. Wysocki SJ, Hahnel E, Masters A, Smith V, McCartney AJ, Hahnel R: Detection of pS2 messenger RNA in gynecological cancers. Cancer Res 50(6): 1800-2. 1990 Mar 15

II. Lefebvre O, Chenard MP, Masson R, Linares J, Dierich A, LeMeur M, Wendling C, Tomasetto C, Chambon P, Rio MC: Gastric mucosa abnormalities and tumorigenesis in mice lacking the pS2 trefoil protein. Science 274(5285):259-62. 1996 Oct II

12. Metaye T, Millet C, Kraimps JL, Aubouin B, Barbier J, Begon F: Estrogen receptors and cathepsin $D$ in human thyroid tissue. Cancer 72(6): $199 \mid-96$. 1993 Sep 15

13. Sagol O, Yorukoglu K, Tuna B, Ozer E, Sis B, Guray M, Mungan U, Kirkali Z: Expression of pS2 protein and its relation with the $\mathrm{Ki}-67$ proliferative indices and tumor recurrence in superficial bladder carcinomas. Eur Urol 200I, 40(2): 163-8.

14. Weinstein MH, Partin AW, Veltri RW, Epstein Jl: Neuroendocrine differentiation in prostate cancer: enhanced prediction of progression after radical prostatectomy. Hum Pathol 1996, 27(7):683-7.

15. Krijnen JL, Janssen PJ, Ruizeveld de Winter JA, van Krimpen H, Schroder $\mathrm{FH}$, van der Kwast TH: Do neuroendocrine cells in human prostate cancer express androgen receptor? Histochemistry 1993, I00(5):393-8.

16. Bonkhoff $\mathrm{H}$, Stein $U$, Welter $\mathrm{C}$, Remberger K: Differential expression of the pS2 protein in the human prostate and prostate cancer: association with premalignant changes and neuroendocrine differentiation. Hum Pathol I 995, 26(8):824-8.

17. Colombel M, Dante R, Bouvier R, Ribieras S, Pangaud C, Marechal JM, Lasne $Y$ : Differential RNA expression of the pS2 gene in the human benign and malignant prostatic tissue. J Urol 1999, 162:927-30.

18. Ather MH, Abbas F, Faruqui N, Israr M, Pervez S: Prognostic impact of neuroendocrine differentiation in prostate cancer. Fourth international symposium on Urology, Nephrology and transplantation and Fourth international symposium on urology and transplantation, transplantation society of SAARC countries $200 \mathrm{I}$.

\section{Pre-publication history}

The pre-publication history for this paper can be accessed here:

http://www.biomedcentral.com/1471-2490/4/14/prepub
Publish with Biomed Central and every scientist can read your work free of charge

"BioMed Central will be the most significant development for disseminating the results of biomedical research in our lifetime. "

Sir Paul Nurse, Cancer Research UK

Your research papers will be:

- available free of charge to the entire biomedical community

- peer reviewed and published immediately upon acceptance

- cited in PubMed and archived on PubMed Central

- yours - you keep the copyright
BioMedcentral 